\title{
Front-line service managers' misbehaviour and disengagement: the elephant in the store?
}

\author{
Anastasios Hadjisolomou, University of Strathclyde, Glasgow (UK)
}

\begin{abstract}
:
Although research has fruitfully located the powerlessness of front-line managers as a central theme in their analysis, the complexity of the front-line management position within the social relations of interactive service work and their 'logic of action' within their labour process remains a relatively marginal theme in research. Indeed FLSMs' position within the triangle, where managerial work is subject to degradation and trilateral conflicting dynamics and their battles within their own labour process still remain under-explored. This study addresses this research lacuna focusing on the FLSMs' experiences on the front-end and their actions of misbehavior within their labour process.
\end{abstract}

This is a peer-reviewed, accepted author manuscript for the following in-press research article:

Hadjisolomou, A. (2019). Front-line service managers' misbehaviour and disengagement : the elephant in the store? Employee Relations. DOI: 10.1108/ER-06-2018-0176 


\section{Introduction}

This article builds on the extensive literature on sociology of service work and re-visits discussions on managerial work, seeking to re-examine the front-line service manager's (FLSM henceforth) position within the service triangle, the organization of the (front-line) managerial labour process and to understand the power dynamics within this role. It seeks to explore the FLSMs' experiences on the sharp-end, what they do and how they react towards the triangular power structure in food-retailing and to understand the "pragmatic and contested realities of frontline customer service management' (Bolton and Houlihan, 2010; p.399 Lloyd and Payne, 2014; Lopez, 2010). The article challenges the assumed unitarist and 'consensus' standing point for FLSMs in organizations (Gilbert et al, 2015; Van Wayenberg and Decramer, 2018) and brings forward questions of agency that remain under-developed by scholars, unveiling 'stories of battles' [as Bolton and Houlihan, $(2010 ; 397)$ call them]. Calling on Geare et al's (2014) call for HRM research to embrace a pluralist analysis, this study recognizes the plurality of interests within the employment relationship, as well as across the different levels of management, placing emphasis on the importance of FLSMs' insights. The article examines FLSMs as 'misbehaving agents' (Willmont, 1997; 1338), a question that lacks empirical evidence as it is only superficially addressed in resistance and managerial studies.

Following Bolton and Houlihan's (2010, p.379) influential account, this article suggests that the day-to-day managerial reality on the service front-line remains 'ghostlike' in both management and sociology of service work literature. Although research has widely explored the front-line service worker, their labour process, and the contested worker-customer relationship (Bélanger and Edwards, 2013; Korczynski, 2013), interestingly, little empirical attempt has examined the role of FLSM and their labour process within this triangular relationship. This suggests that there is still an ongoing need for theoretical and empirical 
development to understand the FLSMs' lived experience within the complexity of service organizations (Bolton and Houlihan, 2010).

Some authors have usefully located the powerlessness of front-line managers as a central theme in their analysis in relation to top-down centralized control systems and competing demands within the service triangle (Bolton and Houlihan, 2010; Lloyd and Payne, 2014; Lopez, 2010). Yet, the complexity of the front-line management position within the social relations of interactive service work and their 'logic of action' within their labour process remains a relatively marginal theme in research. Indeed FLSMs' position within the triangle, where managerial work is subject to degradation and trilateral conflicting dynamics (Lloyd and Payne, 2014) and their battles within their own labour process (Bolton and Houlihan, 2010), still remain under-explored. To contribute to these two theoretical and empirical lacunas this study has two research objectives: (1) To examine the organization of front-line managerial service work and (2) To understand how FLSMs express agency over their intensified role in service organizations.

In order to explore FLSM agency issues, the framework of the dimensions of misbehaviour, as developed by Ackroyd and Thompson (1999), is adopted. The concept of misbehaviour is appropriate because it seeks to capture recalcitrant agential practices that do not necessarily constitute intentional, upwardly-directed resistance. Furthermore, the four categories of misbehaviour - appropriation of time, work, product and identity - allow for the diversity of FLSM practices to better described and understood.

The article is organized as follows. Firstly, an overview of the literature is presented, debating the neglect of managerial resistance within critical studies on service employment. Next, the methodology is outlined, with the findings presented in the third section. Finally, the article discusses the theoretical and practical implications of the research. 


\section{FLSMs muddling in the middle: Powerlessness and resistance?}

Industrial sociologists have long discussed the contradictory pressures from above and below, with supervisors being 'trapped' as a middle strata worker between labour and management. On one hand, they interact daily with the workers they supervise, but they are also part of the management team, receiving orders from their superiors, and experiencing pressures to conscientiously act in favour of the management. (Child and Partridge, 1982). However, as Willmont (1997; 1340) fruitfully recognizes, 'managers are not judgmental ropes who slavishly perform the functions of the capital'. The author, following Braverman's argument that management itself is a labour process, describes managers as misbehaving agents, whose labour power is deployed to supervise the worker's labour process (to secure capital accumulation), but at the same time it is similarly commodified and subjected to the disciplines of capital accumulation (p.1338).

Students of managerial work have conventionally focused on the abstract and traditional functions of management, where they are portrayed as compliant functionaries who unproblematically perform the tasks demanded by capital (Willmont, 1984; 1997). Surprisingly this remains problematic within the contemporary sociology of work and managerial literature, which assumes a unitarist ideology in management, neglecting the political realities of management and the complex and contested nature of (front-line service) management work. FLSM is, of course, in an agency relationship with capital, to use Armstrong's (1989) wellknown term. However, that is not inconsistent with recognizing the different dynamics and the heterogeneity in interests at different levels of management (Thompson and McHiugh 2009), as the pluralist ideology suggests.

Geare et al. (2014) have provided a useful insight on the ideological undercurrents of HRM, revealing a mixed picture of managers' ideology. While authors have challenged the oversimplified dichotomy of unitarism and pluralism in a perfect sense, it remains true that the 
unitary view is a "taken for granted assumption" in HRM research (Geare et al., 2014; Keenoy 1999, p. 2). Indeed, much of the HRM line managers' literature is 'inseminated' by a unitarist approach assuming that line managers conscientiously bring policies to life' (Purcell and Hutchinson, 2011) and incontestably act as 'ambassadors' of senior management to the frontend in line with the organisational strategic goals (Janssens and Steyaert 2009; Van Buren et al., 2011).

As LaNuez and Jermier (1994) suggest, however, managers' interests and objectives (Geare et al. 2014) do not always intersect with those of capital, therefore they may act in contrast to the capitalist's interests. As the former authors report, for reasons similar to those of workers, some managers resist capitalist domination, concluding that resistance is not practiced exclusively by employees but also by managers. Richards (2008; 663) similarly highlights, 'managers misbehave too'. Richards (2008) locates such misbehaviour as the outcome of managers working in pressurized working environments and utilizing strategies that deviate from the official script, suggesting that they are resisting pressure put upon them by more senior management.

This is particularly true of service operations. Indeed, the traditional 'supervisory problem' has been reconfigured, with the relative 'powerlessness' of FLSM being a central theme in the literature. Lloyd and Payne (2014), for example, find that FLSMs are highly constrained by the centralized control applied by head office and, similarly to Bolton and Houlihan (2010), suggest that they had to mediate between the head office and their staff. As Townsend and Hutchinson $(2017 ; 7)$ similarly highlight, 'line managers are not only a manager of other employees but also a subordinate, and can be in conflict in their relationship with senior managers'. Understandably, FLSMs are 'stuck in the middle' of conflicting demands of the different groups they are interacting with. They have to maintain cooperation with their subordinates, and at the same time meet the top management requirements. 
The picture however becomes even more complex in the context of services, such as food retailing front-line service, where managers mediate between the head office/senior management, the employees, and the customers (Bolton and Houlihan, 2010; Lloyd and Payne, 2014). The involvement of the customer in the labour process (Lopez, 2010), the sovereign customer (Korczynski 2013; Korczynski and Evans, 2013) and the triangular conflicting dynamics are sources of pressure for both employees and managers (Lloyd and Payne, 2014). As Bolton and Houlihan (2010; 381) acknowledge, FLSMs are not a 'distant figure', but are actively situated in the triangular dynamics within which they face difficulties of "muddling along in the middle', receiving and managing mixed messages and difficult demands. Surprisingly academic debate on resistance and recalcitrance has tended to neglect FLSMs' responses to these pressures and the organizational control, especially in the contemporary service economy, where managerial work is subject to degradation and trilateral conflicting dynamics (Bolton and Houlihan, 2010; Lopez 2010; Lloyd and Payne, 2014).

The framework in this study is useful to address this omittance by recognizing the contested nature of front-line service management work and exploring FLSM's agency within the service triangle, a neglected theme in resistance and managerial literature. As Thompson (2016) notes resistance and misbehaviour are inevitably caught up within the complex dynamics of the 'service triangle', whilst Edwards and Belanger (2010) report on service sector studies which discuss the growth of low skill service work as enhancing the opportunity for forms of misbehaviour, as employees search for dignity and a means of defense against work pressures. Nevertheless, there is predominant focus in the literature on the front-line service worker, their labour process, and of course the contested worker-customer relationship (Bélanger and Edwards, 2013; Korczynski, 2013). Some research has referred to (front-line) managers' turnover (Lundberg and Karlsson, 2011) or their actions of turning a blind eye to employees' misbehaviour (Royle, 2000). However there is limited empirical analysis of FLSMs' 'battles' 
within their own labour process. This is consistent with Bolton and Houlihan (2010), who argue that we should not infer that FLSMs are without agency and report that their participants shared stories of 'battling'. Yet even these latter authors fail to provide sufficient, if any, empirical evidence to sustain this narrative.

Such assertions of oppositional practices or 'battles', as Bolton and Houlihan call them, need to be contextualized with reference to the specific empirical object, notably the managerial policy and the available power resources present in the context (Thompson, 2016). Although LaNuez and Jermier (1994) have long highlighted managers' willingness to engage in forms of deep opposition, this concept remains underdeveloped and overlooked in contemporary studies, whilst the context within which opposition is devised is partly neglected and has received limited attention (Ackroyd and Thompson, 2016). Lloyd and Payne (2014) call for further empirical studies that focus on the realities of front-line managerial work to other parts of the mass service economy. This study examines the FLSM on the food-retailing shop floor and their contested day-to-day reality and labour process, emphasizing the need to modernize these debates and analyse the contested managerial labour process within the service economy. This will allow service research scholars and organizations to further understand the complex dynamics of FLSMs' work, to recognize the variety of interests amongst management and develop appropriate policies and practices to reflect the contested pragmatic realities on the front-end, away from assumptions of harmony and common identity between senior and frontline managers.

Using Ackroyd and Thompson's (1999) framework of dimensions of misbehavior, this article identifies, categorizes and conceptualizes FLSMs' (mis)behaviour on the shop floor as a response to the expansion of their role on the front-end and their involvement in the triangular dynamics and customer service management. Within this analysis, the article accepts Thompson's (2016) argument that this pressurized managerial regime evidences 
disengagement by FLSMs from corporate values, as a way of distancing from organizational commitment, which is linked to misbehaviour. Thompson $(2016 ; 118)$ locates misbehaviour within a 'continuum of oppositional practices in which misbehaviour denotes a broader category of things you are not supposed to do, think, or be'. This article adopts the argument that 'the boundaries between what is often perceived as misbehavior or disengagement on the one hand, and resistance on the other, have become blurred (van den-Broek and Dundon 2012; 116). Therefore, it uses the four dimensions of misbehaviour (appropriation of time; work; product and identity) to describe and explain the FLSMs' agency and 'battling' tactics within their labour process and the pressures within the triangular service relationship.

\section{Methodology}

The article calls on qualitative data from two case study organizations in the Cyprus food-retail sector, during a period of austerity when Cyprus was facing recessionary pressures. This sector provides an interesting site of investigation. Traditionally dominated by home-grown grocers, the market has faced dramatic changes in the past decade with multinational grocery and discount retailers entering the market. This, in addition to the recession in the country, has generated pressures for cost cutting practices and led to an intensive price war and measures by organizations to reduce labour costs, as well as pressures for customer retention. This has led to further developing service cultures containing the values of 'the customer is king' and the intensification of front-line managers' and employees' work.

The research used a multiple case study approach which has offered an in depth within-case and the cross-case analysis and enabled the researcher to understand better the social relations on the food-retail shop floor, the organization of the FLSMs' work and their daily reality. Given the focus on a specific national context, the vital issue of generalizability is present in this study. The inclusion however of both multinational and home-grown organizations in the 
analysis gives confidence for the theoretical generalisation of the data (Partington, 2002) and contribution to the theoretical grounds adopted for this research.

RetailEU is a world leader grocery-retailer with presence in Cyprus since 2005. Although a smaller organization, RetailCy has seen a steady increase in its market share. It is a leader in its region and is expanding its business to other areas of the island, becoming today the second biggest home-grown food retailer in the country. The two case study organizations were selected based on their size, their market share, and the measures taken by management to 'survive' the recession.

Indeed, the start of the recession in Cyprus pushed the two case study organizations to take cost-cutting measures because of the aggressive price war in the market and the increasing financial cost which was aggravated by recessionary pressures. Both organisations responded to the recession through a variety of measures to reduce labour costs. Interestingly these measures not only targeted employees, but also front-line and middle managers. Specifically, RetailCy introduced a 5\% of pay cut for managers, whilst RetailEU proceeded with closing departments, restructuring, redundancies, recruitment freezes and pay cuts which affected both shop floor employees and FLSMs.

Qualitative research data was secured using semi-structured interviews enabling broader and deeper understanding of the social phenomena under investigation [service triangle relations, FLSMs' (mis)behaviour]. Interviews lasted between 35-90 minutes. In total, forty-six interviews took place; twenty-five in RetailCy and twenty-one in RetailEU. A purposive sampling strategy was followed. This sought for information-rich cases and participants on the front-end and across the shop floor who interacted with customers directly (both employees and FLSMs), as well as those at higher levels of authority who were involved in shaping customer service culture in each organization (senior and store managers) and to whom FLSMs report. 
The concept of 'saturation', as a widely accepted practice in qualitative research, was followed in this study to determine the sample size. Advocating the conclusion by Guest et al. (2006), it is argued that the homogeneity of the sample group gives confidence to the data and suggests that the number of interviews is sufficient to achieve the desired research objectives. Interviews with shop floor employees were deeply insightful as they were in daily and constant interaction with FLSMs across the shop floor. Employees from both organizations worked in different departments across the shop floor (shelves, checkouts, customer service) and had direct interaction with FLSMs and customers. Notably, all employees were trained to operate checkouts and they provided front-end assistance on a daily basis, which gave vital information on the organizational daily reality across the shop floor. Additionally, in total eight FLMs from both the checkouts and the shop floor departments were interviewed, whereas two store managers and two senior managers participated, providing useful insights regarding the organization of work on the shop floor, the primacy of customer service quality, and relations across the service triangle, as well as observations regarding FLSMs' behaviour.

The conventional term 'front-line (service) manager' is used to identify and describe those managers who sit at the first level of the managerial hierarchy and are responsible for managing a department on the supermarket shop floor, including checkouts, shelves and butchery. They engaged in a general management role and interacted directly with the front-line employees, however they had more responsibilities than just supervising. These FLSMs, similarly to their subordinates, had a direct interaction with the customer and had a significant role to play in customer service.

The interviews focused upon a number of key themes, including the nature of work, the FLSMs responsibilities and tasks, their involvement in customer service, the day-to-day reality on the shop floor and actions of misbehaviour by FLSMs. Participants were asked to describe and 
narrate the day-to-day reality on the shop floor, to identify issues within customer service and discuss the role and actions of FLSMs within the daily service reality.

Thematic analysis, the most widely used strategy to analyse qualitative data, was followed in order to achieve a deep analysis of the collected data. The "Coding Tool" (data reduction) was utilized to organize and analyse the transcripts produced across the two cases, which were more than 130,000 words long. Particularly, the process of open, axial and selective coding was used in order to disaggregate data, to discover patterns, recognize relationships between themes and produce integrative categories (Saunders et al., 2009). This process of coding was subject to revision. The vast amount of data required a strategic and careful development master codes and sub-codes in order to be able to organize the emerging findings and be able to provide a comparison not only between the two cases but also across departments. This has allowed the development of a (multipart) matrix which helped to identify the conceptual themes across the different cases and allowed a theoretical comparison.

The findings begin by outlining the FLSMs' role, making a distinction between checkout and shop floor managers and briefly highlighting the expansion of both roles. The next section, using the Ackroyd and Thompson's (1999) dimensions of misbehaviour framework, conceptualizes the FLSMs' actions of opposition and identifies the different tactics utilized, depending on the level of customer interaction and their mobility on the shop floor.

\section{The front-line management role: expansion and intensity}

The data reveals similar operational and managerial tasks and responsibilities for FLSMs in similar departments across the two organizations. For example, shop floor managers [food and non-food sections] were responsible for monitoring product stocking, displaying prices and offers and stock management, whilst also being held accountable for incomplete tasks and issues on the shop floor. 
Discussions with checkout managers similarly revealed almost identical responsibilities across both organizations, such as managing cash, making returns, and correcting scanning/sales mistakes. In both cases managers commented that they could not leave the front-end because these mistakes were very common, and without their electronic key employees could not proceed with the service.

Similar to their subordinates, but unlike other shop floor FLSMs, checkout managers had a daily, direct and constant interaction with the customers. Customer-centric tasks can therefore be said to be embedded in the checkout manager's role. As the Store.manager1/RetailCy argued, shop floor managers had greater mobility to walk around the shop floor, whilst there was always one checkout manager present on the front-end/checkouts at all times:

'The shelves managers, you usually find them in the warehouse carrying out paperwork rather than dealing with customers. This is the checkout manager's job.' (Store.manager1/RetailCy)

Indeed, the interaction with the customer was the most vital part of the checkout manager job: 'My job is to keep the customer happy. We are here to serve them, to listen their problems and complaints. Whatever happens... we need to listen and find a solution for them.' (Checkout.manager1.RetailCy)

In both cases, FLSMs discussed the expansion, and in some cases the perceived excessive workloads devolved to their role and the impact on their working experience. For instance, the shelves manager in RetailEU commented that she often had to 'roll up her sleeves' [sic] and assisted her employees in stocking, tidying up and dusting the shelves due to the limited number of staff available due to the recent cost-cutting redundancies within the store. The frozen-food manager in RetailEU similarly commented: 
'I am now responsible for orders, stocking and cleaning... they reduced our staff and gave us more responsibilities'

A checkout manager in RetailEU expressed a similar view commenting that due to shortage in labour there were fewer employees available to serve the customers and often, especially on busy days, the customers were complaining, as the queues were longer.

Senior management in both organizations acknowledged the pressures on the checkout managers' role due to the limited mobility and the constant interaction with the customer. Additional data illustrated the expansion of the checkout FLSMs' role in the two companies, with evidence of extra responsibilities being placed on them. In RetailEU, checkout managers were responsible for running the kiosk, while simultaneously monitoring the front-end, and carrying out their supervisory/managerial responsibilities. They argued that in rush hours they felt stressed and unable to complete both tasks:

'When it's busy that's me running up and down the shop floor to sell tobacco on the kiosk, and to check that the checkouts work fine. It's not an easy job, I literally have to be in two places on the same time.' (Checkout.manager2.RetailEU)

A similar situation was found in RetailCy. Over the last few years, the organization had devolved extra responsibilities to checkout managers, for example, the preparation of orders for organizations such as, but not limited to, restaurants. According to participants this was an extremely time-consuming task and they reported increasing pressure within their role:

'We have so many responsibilities... we have to manage the products, the offers, the customers and the employees...some days the pressure is just so high that I get to the point to say that I cannot do this anymore. It's a tough job, because there are so many things we deal with; the girls, the restaurant orders, the customers.'

(Checkout.manager3.RetailCy) 


\section{Oppositional actions and disengagement by front-line managers}

The multiple responsibilities devolved to the frontline evidently generated feelings of pressure for FLSMs. Interestingly, the data revealed that FLSMs utilized various tactics to oppose the increasing workload and the expansion of their role. The data also highlighted the difference in tactics used by checkout and shop floor workers to mitigate the impact of these additional responsibilities. The article below classifies these tactics using the four dimensions of misbehaviour (Ackroyd and Thompson 1999), namely: appropriation of time; work, product and identity. Appropriation of time and work are analysed as synonymous concepts as the tactics included in these two categories can overlap (Thompson, 2016).

\section{Appropriation of work and time}

\section{Effort - bargaining}

A common theme that emerged across the two organizations was that FLSMs 'don't care anymore' [sic], clearly suggesting FLSMs' disengagement with their job and the appropriation of effort. Interestingly, participants have suggested that the focus on costs in the two organizations and the recent cut in FLSMs wages was the driver for their effort-bargaining tactics. As a senior manager/RetailCy commented:

'[After the cut of wages] they [FLSMs] are not interested anymore. They might see things happening and they say who cares.'

Although only one FLSM admitted to 'putting less effort' in his job because, as he commented, 'we are not valued anymore, so I only do what my [current] salary is for', senior managers' responses did confirm this effort-bargaining (mis)behaving approach by FLSMs. A senior manager in RetailCy discussed the case of a shop floor manager with long tenure in the organization with great performance, who, after the cut of wages, demonstrated decreased performance and limited effort in his job. The shop floor manager left the task of stock management, for which he is responsible, to the warehouse employee which resulted in the 
store warehouse and the store in general becoming understocked. The senior manager/RetailCy stated:

'He [shop floor manager] had full control of the warehouse. Now the store shelves are empty...After the cuts in wages he just doesn't care anymore of what's happening in the store, he is just not interested anymore. He probably thinks that the company does not appreciate what he has offered all these years. Therefore, he acts in this way.'

This manager suggested that the cut in wages resulted in a wave of misbehaviour such as putting in minimum effort to the job and limited commitment to the organisation by managers of different parts of the shop floor, across multiple stores. Data in RetailEU showed similar incidences with FLSMs across the shop floor displaying limited commitment to the organization and refusing to go the extra mile, particularly after the redundancies and restructuring.

Employees, in both cases, reported that FLSMs were doing the bare minimum when it came to their everyday tasks. A checkout employee in RetailCy commented that her line manager was not interested in her job whilst a Checkout.employee15 in RetailEU similarly noted:

'She just waits [for time to pass] to go home. She is coming in, always bored and fed up...And when you call her for a cancellation or anything, after you called her three or four times, she always moans about it. She goes like 'aww not again, I'm tired'... She always disappears 10 minutes before the end of the shift. She doesn't care'.

\section{Time appropriation}

The quote above illustrates FLSMs' recalcitrance expressed not only through effort appropriation but also time appropriation. This was common for FLSMs, both those on the front-end (checkout managers) and those on the shop floor (i.e shelves managers). Both 
employees and managers have discussed how FLSMs were appropriating time on the shop floor and often did the minimum of what was expected. The latter argument was raised by the frozen-food line manager in RetailEU, who admitted that he was taking longer breaks or was away from the shop floor in the warehouse:

'Sometimes I was on a break for 45 minutes rather 30', or I was just sitting in the warehouse having a laugh with the girls...[On the shop floor] I was leaning on the fridge and I was watching them [employees] stocking the meat. I could help on stocking but sometimes you just loaf, everybody do that sometimes.'

A senior manager in RetailCy observed and described similar incidences for the food-section and non-food-section line managers. This respondent angrily commented that such managers were constantly away from their post, attempting to avoid their responsibilities or finishing their shift earlier:

'[Shop floor FLSMs] have become clock-workers, just like a normal employee, looking forward for the time to finish...A week ago on the change of their shift one of them was already gone $15^{\prime}$ earlier and the other one had not arrived in work yet. Managers do not have rotas...I'll stay until work is done, so should they...these people do not act as managers' (Senior.Manager.RetailCy)

The quote above clearly illustrates the [unitarist] expectations by top management for FLSMs to 'act as managers', requesting a common approach and commitment across the management team. Yet, as the data shows, the shop floor reality is different with FLSMs pursuing their interests via actions of time appropriation. This is also reflected in employees' responses who discussed, for example, that some shop floor managers across both organizations and across different departments, appropriated time by utilizing their freedom to be mobile around the store, to step away from the floor and their responsibilities. This mobility provided them space 
to appropriate time, express disengagement and battle the organization of their work. A checkout employee commented:

'They all do it...Last Saturday it was so busy in here and the non-food manager was outside in the parking speaking on his phone. But when one of the senior managers pop down on the shop floor they either disappear in their office or they come on the front-end pretending they talk to the customers. It's like while the cat's away, the mice will play, you know. But when the cat [senior managers] shows up they try to show off how hard they work, ha!'(Checkout.employee12.RetailCy)

Such mobility, however, was not universal. In the case of checkout managers, the way they appropriated time was different. Although their job demanded them to be constantly present on the front-end, they still managed to develop tactics to challenge the demanding and expanded front-end job. Employees in RetailEU commented that checkout managers would be deliberately absent from the front-end, pretending to be busy on the kiosk. One employee/RetailEU commented:

'They are chatting on the kiosk and they ignore our calls. Once I said to them in a cheeky tone: 'Sorry for interrupting, can I have some change?' They ignored me again, and I then had to shout for them to response. This happens a lot!'

This showed that although checkout managers were not necessarily physically absent from the shop floor, they were mentally withdrawn, pretending to be busy, or ignored employees' call, thus avoiding the routine process of correcting mistaken scans or dealing with returns. Employees in both organizations described cases when they asked the checkout manager for assistance and the latter were 'unhurried' in providing help, justifiably, disengaging with the need for speed in their job. As one employee in RetailCy stated: 'They are so slow, taking their time, while the customer moans' 
Similar actions were found in RetailEU with checkout managers being sluggish when assisting the employees:

'You call them to do a cancellation and they ignore you...she is standing there texting to her boyfriend. She will say 'one minute' and getting upset because you ask her to do her job. She then comes there and she is like 'can you not see I'm on the phone?!' She will walk towards me slowly, no rush, no interest if the customer is waiting.'(Checkout.employee7.RetailEU)

These incidences were acknowledged by senior management participants, in both cases, who have put forward the argument that FLSMs: 'Obviously don't care' (sic: Senior.Manager1.RetailCy]. This suggests that FLSMs are disengaged with their role, a behaviour which can be seen to be at odds with standards expected of senior management. This view by senior management again fails to recognize the variety of interests across management, 'pointing the finger' to FLSMs for not complying with organizational goals. This is clearly evident in the discussions regarding FLSMs' involvement in customer service as discussed below.

\section{Avoiding rude customers}

As the data illustrates, the customer-driven job on the front end was indeed subjected to oppositional tactics by checkout FLSMs. As discussed, these are managers who interacted directly with the customers on a daily basis. In both cases, however, senior management respondents recognized that FLSMs avoided the responsibility of dealing with aggressive customers, although dealing with customer complaints is a key part of their role. A senior manager in RetailCy also commented: 


\begin{abstract}
'The girl on the information desk receives all the complaints and I feel sorry for her. Every angry customer yells in her face...she is not actually the one who is authorized to manage these issues, she is just the messenger to the [front-line] management team, [but]...[FLSMs] are hiding in the aisles. They do not even approach the desk when an angry customer is present.'
\end{abstract}

This manager suggested that the stores' layout allows FLSMs to act in this way. As she described, the customer information desk is, in the majority of the stores, located away from the checkouts and closer to the entry of the store rather than the exit. Therefore, FLSMs use the excuse of not hearing the customer complaining and therefore avoid dealing with them. She continued:
'Often the checkout managers when they hear a customer shouting might go and stand at the very end of the checkout area, behind the last desk, pretending she cannot hear or see the customer who is complaining. It's very often for problems and mistakes to happen and we have to manage them, not avoiding them.'(Senior Manager2.RetailCy)

This senior manager participant commented how FLSMs do not fulfil their roles and avoid essential parts of their role on the front-line, describing this again as an 'unprofessional behaviour'. Similar incidents were revealed in RetailEU, with FLSMs often sending customers to the Store Manager's office, handing away this responsibility. He commented:

\begin{abstract}
'If they see an aggressive customer they will leave the employee alone to manage it. If the customer approaches them first they will deal with it because they cannot avoid it, but even in this case they just send the customer to someone else. There are so many times I had customers in my office sent by the checkout manager... They just don't want to deal with angry customers... They should just stop avoiding this responsibility'
\end{abstract}

(Store.manager.RetailEU) 


\section{Appropriation of identity \\ Avoiding responsibility}

The quote above also links to the appropriation of identity by FLSM, focused particularly on avoiding or negating managerial responsibility. The data below shows the inconsistency between senior management's expectations of FLSMs' role in the organization, and the dayto-day reality within which FLSMs are perusing their own interests.

There is persuasive evidence in the data suggesting that FLSMs expressed their desire to have responsibilities taken away from their role. Senior managers in both organizations emphasized the latter argument, asserting that FLSMs avoided taking on any responsibilities or making decisions. For example, the store manager in RetailEU suggested that FLSMs did not want to take responsibilities related to the employment relationship. Similarly, a senior manager in RetailCy highlighted FLSMs' hesitation to carry out the tasks attached to their managerial role. He discussed the lack of competences and the reluctance to identify themselves as part of the management team:

\footnotetext{
'They perceive themselves as workers and not managers...because they've progressed from the shop floor... and this is obvious by the fact they avoid to take any decisions...for example, an employee calls in absent, they will go straight to Costas [store manager] to ask for guidance, they don't take the initiative to cover the absence...I strongly believe they lack the skills to deal with management issues and I don't believe most of them have got the instinct of responsibility'
}

Similarly, one checkout employee in RetailEU discussed the case of a particular FLSM who always refused to take any absence calls and directed employees to contact the store HR manager, despite the guidance given by the top management that the line manager should be the first point of contact. 
Indeed, FLSMs regularly appeared to seek approval from senior management in carrying out the tasks delegated to them in relation, not only to their managerial and HRM role, but also their role within customer service. Senior.manager2 in RetailCy reported that they constantly sought approval, even for unimportant tasks:

'The National Hospital is one of our biggest customers. On Christmas they asked for a free cake with their order. The checkout manager in Store3 called the Head Office to ask us whether to send the free cake to the hospital. This is ridiculous, the cake costs $€ 2.50$ and we have thousands of income from the hospital every year. It's just a cake, send it and you don't really need anyone's approval... They just want to keep their back safe. If someone asks them why, they will say that I told them to do so. They just pass the responsibility to someone else.'

In interviews with FLSMs, they voiced their fear of being criticized for poor performance, with delegated tasks such as people management being particularly unwelcome. Some respondents commented that they would be the first person senior managers would blame for issues on the shop floor. They therefore chose to always seek confirmation for their actions to avoid being the scapegoat of the management team.

\section{Gossiping, 'bitching' and joking rituals}

The study also shows that FLSMs were utilizing gossip, 'bitching' and humour as mechanisms to express their discontent towards the complexity of their managerial role, the increasing responsibilities and tasks within it, as well as their involvement in customer interaction. Participants, both employees and managers, commented that 'bitching' about management, customers and other employees was a daily phenomenon within both organizations. 
As employees explained, checkout managers in particular were those who gossiped and joked both amongst themselves, as well as with their employees about rude and/or demanding customers. A checkout employee in RetailCy commented:

\begin{abstract}
'Once I had this customer who came to my desk and grabbed a pack of plastic bags and put them in their bag. I politely said to them that they cannot do that and they started yelling that I accused them of shoplifting. In cases like this it's impossible not to comment and bitch about it. We are here to serve these people and we shouldn't be treated like that. Now every time this customer comes in the store everybody [including FLSMs] goes like: 'quick hide your bags' and we all have a laugh about it.'
\end{abstract}

Evidently, employees and FLSMs are involved in joking and gossiping rituals as a reaction to the commonly aggressive behaviour by customers. RetailCy data showed that customer namecalling was a common practice to develop a ritual of joking and bitching towards customer demands and the emphasis on 'keeping the customer happy'. This was a way to develop a collective space of discontent on the front-end.

A checkout manager in RetailCy described two incidences where customers became the 'butt of the joke' amongst store employees. She discussed one customer who returned an opened and half-empty bottle of wine, naming the customer as the 'undecided-alcoholic', and another customer who returned a cooking pan with food stuck to it. The latter complained that the pan was not non-stick, therefore brought the used pan as a proof, and demanded their money back for both the pan and the food ingredients. She named this customer as the 'Dominos customer'. She commented:

'We get ridiculous demands like that all the time... She was yelling at me for her burned stew in front of other customers and the girls [employees]. We gave her the money back 
[for the pan]. I did it with a smile saying: 'oh I'm so sorry' but in my head I was like: 'I'm so sorry you don't know how to cook, here's the Dominos menu'. I could see the girls sharing a laugh afterwards; we were talking about it for months. We are waiting the next one [customer] to top this.'(Checkout.manager4.RetailCy)

FLSMs in RetailEU shared similar stories of 'sharing a laugh' as the customers are becoming more demanding. A shop floor manager commented:

It can be very hard, dealing with them. Some customers, they have complaints for things that we just can't help...we got someone complaint because a pigeons outside "messed" his car, how do you deal with this? We have a lot of things in control, but we don't own the pigeons...we get a good laugh at these customers.'

In both organizations, FLSMs allowing or even initiating these joking rituals on the shop floor develop a community of coping and expressing discontent towards the 'customer is the king' mantra within each business. Yet, more data suggests that gossiping and bitching is not only targeting customers but also targets employees, and even store and senior managers. Senior manager2/RetailCy discussed 'gossiping' as misbehaviour by FLSMs and an action that does not reflect their managerial status, questioning their position in the management team. She commented:

'Recently [rumours say] a girl was shagging the store manager in Store3. He is married and his daughter is working on the checkouts. The amount of gossip was beyond imagination at the time. Everyone knew about it, from the man in the car park to everyone on the shop floor. And this had started from the checkout manager. It's her who gossiped about it to the employees and then the employees just spread the news...I mean you are a manager you cannot put yourself in the same level as your employees, no matter how much you like gossiping.' 
This quote reveals an assumption of common interests in the management team, with a 'topdown' set of expectations for FLSMs to 'act' in a way that the senior management deems appropriate. Senior management fails to recognize however the contested daily front-end reality and the use of joking and gossiping rituals by FLSMs to express agency towards their involvement in customer service and the direct interaction with sovereign customers. Overall, FLSMs have been found to use gossip and humour in two ways. Firstly, it was a way to 'ridicule' the customer and react to the customer sovereignly, through creating a community of coping on the front-end and secondly to undermine the store and senior managers' authority. This could be explained as a way to challenge increasing pressures emerging both from 'above' as well as within customer service.

\section{Appropriation of product Thefts and pilfering}

Finally, participants in RetailCy discussed many cases of FLSMs being involved in cases of theft and pilfering. This theme did not emerge in the data in RetailEU. This could have two explanations. First is the closer surveillance by the store manager and head office, as well as policies in place to prevent such actions. Stock management was a centralized process in RetailEU, whilst regular stock monitoring was conducted by the head office. Therefore it was more likely to identify inconsistencies in stock and sales. In contrast, in RetailCy stock management was carried out at a store level, which delayed the identification of inconsistencies in stock levels and therefore the conduct of investigations for theft/pilfering.

A number of actions of pilferage were discussed by the senior managers in RetailCy, whereas employees did not comment on such incidences by their managers. The two senior managers suggested that it was usually the FLSMs who dealt with stock and those who had freedom of mobility on the shop floor that were involved in these actions. Interestingly data have not 
revealed similar incidences for checkout managers. This can be explained by the limited space for pilferage actions by these managers as they were exposed to customer's direct 'monitoring' on the front-end.

One senior manager discussed the case of pilfering by one of the shop floor managers in a remote store. He commented that this shop floor manager had the key for the main door and he was responsible for opening the store every morning at $7 \mathrm{am}$. By this time he was the only one who had access inside the store area and as it was discovered later, he was stealing tobacco from the kiosk and then was selling it to employees inside the organization at half-price. This had raised suspicions within the organization, therefore they conducted an investigation and caught him stealing the tobacco through CCTV. After a stock review and investigation, it was found that he had stolen tobacco worth of $€ 20,000$ in a period of 38 days.

The kiosk seemed to be a popular area for pilfering as, according again to the senior managers, it was an area with valuable items, such as tobacco, and small items that someone could easily put in their pockets. In a different store, the shop floor manager again was involved in an action of pilfering. Similar to the previous case, this manager was the last one who left the store and the one who was responsible for locking the main door and closing the shop. In this case the manager used to issue phone top-up tickets before leaving the store. The investigation revealed that he issued tickets totalling $€ 575$.

Senior.manager2/RetailCy linked these incidences of theft and pilferage to the recent salary cuts. She commented that such actions by managers were a new phenomenon in the organization, and that these emerged after the salary cut:

'I don't know why a manager would steal, I just don't get it. I know that their salary is not very high, but it is definitely higher than employees. What is interesting is that 
there is indeed an increase of such incidences by FLSMs after the salaries cut two years ago. Maybe this is their reaction to the reduced income'.

This same participant also described the case of the butchery line manager who was caught transferring meat to the warehouse for personal use without checking it out. She reported that in the disciplinary meeting this FLSM admitted that he had 'stolen' the meat because of the reductions on his income. She commented:

'The butchery manager took $5 \mathrm{~kg}$ of meat and moved them down to the warehouse without checking them out. We caught him on camera doing it. We had a disciplinary meeting and he was fired. During that meeting the store manager said to him: 'if you needed $5 \mathrm{~kg}$ of meat why didn't you ask me to help you somehow, why did you have to steal?'. He said: 'well you cut my money without asking me; why would I ask for your help?'

Although the data has revealed sporadic rather than regular pilfering insistences in only one case study organization, it is important to note that these were not spontaneous but were the outcome of the cost-cutting measures in the organization. As the data suggests, shop floor managers, who had mobility freedom within the store, reacted to the cut in their salary through these actions. These actions were described by senior managers as irresponsible and unnecessary, assuming harmony and commonality of interests across the management team.

\section{Discussion and conclusion}

This paper supports but seeks to go beyond Bolton and Houlihan's (2010) argument that frontline service managers are not without agency. It provides a rich empirical resource on FLSMs' oppositional actions for scholars, contributing to sociological debates related to front-line 
service managerial work and organizational misbehaviour. Although the concept of misbehaviour has been widely applied to employees, here an account of 'managerial misbehaviour' is shown to be a useful addition in understanding the actions of FLSMs within the triangular service relationship, a theme that has been largely neglected in management and labour process literature.

Agency can only be adequately understood in context. Undeniably, FLSMs across the two case study organizations were involved in a demanding working regime, characterised by expanded responsibilities and were subjected to conflicting demands within the service triangle. In continuity to the classic writings on the supervisory problem and the 'men in the middle' argument (Child and Partridge, 1982), it is argued that this becomes more complex in the contemporary service economy, with FLSMs being 'stuck' among the often conflicting interests and expectations of the service organization arising from senior managers, workers and customers' (Bolton and Houlihan, 2010).

A closer look at the case evidence, however, shows that not all FLSMs are directly involved in this muddle of interests, reinforcing earlier observations that management is not a monolithic entity (Townsend and Hutchinson, 2017). The work of Hales $(1986 ; 2001)$ has been particularly influential in analysing what managers do, arguing that managers at different levels carry similar responsibilities with respect to people, information, monitoring and non-managerial activities. Although Hale's vertical analysis of management offers useful insights, this study highlights the importance of a horizontal analysis of management. As Townsend (2014) similarly discusses, line managers are not a homogenous group and although the role shares many similarities across organizations and sectors, aspects of these roles also vary between industry, organizations and departments.

Indeed, as this study shows, even at the same level, the managerial labour process varies, for example between checkout and shop floor managers' tasks and responsibilities. The former 
had a direct and constant interaction with the customer, whilst the latter had a greater mobility on the shop floor and were not necessarily involved in [face-to-face] customer service. This shows that authors have exaggerated the involvement of all front-line service managers in conflicting trilateral interests. These pressures lie more on the shoulders of those who are on the firing line of customer service, in this case the checkout managers. Researchers need to reexamine the particular labour process of these (dis)similar positions within the management team. Following this logic, research should not over-generalize about FLSMs' oppositional practices, as Bolton and Houlihan tend to do, but should examine the working regimes and the structures of control they are involved in.

Scholars of service sector employment, who highlight the conflicting interests in the triangular service relationship, also run the risk of neglecting FLSMs' interests and identity, as well as their actions of battle to protect these. Belanger and Edwards (2013) call for research to further examine front-line service employees' resistance to the asymmetric triangular relationship. This however, still leaves the gap of understanding FLSMs 'lived experience' and contested realities. Although studies have attempted to fill in this empirical omission (see Bolton and Houlihan 2010, Lloyd and Payne, 2014; Roberts, 2008), our understanding and knowledge is still limited. This study shifts the focus of management research away from the traditional agency argument focusing on what managers do for capital (Armstrong, 1989) and towards the sociological enquiry of what managers also do for themselves, discussing FLSMs as 'misbehaving agents' (Willmont, 1997).

This article challenges the embedded HRM unitarist assumption that FLSMs are conscientiously agents of the capital and reveals evidence suggesting the plurality of interests across management. HRM scholars, especially those discussed line managers as HRM partners, have overestimated FLSMs' identification with senior management and the strategic goals of the organization. As the study has shown, FLSMs across the shop floor strongly identify with 
'front-line employees', protecting their own interests within the employment relationship via oppositional actions and disengagement.

To understand evidence of managerial discontent and disengagement in these cases, the article utilizes Ackroyd and Thompson's dimensions of misbehaviour framework. The primary purpose is to capture and differentiate everyday recalcitrant practices and actions of disengagement by FLSMs, without the burden of projecting these as conscious resistance, as well as to identify similarities and differences on how different FLSMs expressed these behaviours. The latter is associated with the variations of FLSMs' tasks and their position on the shop floor. The mobility of shop floor managers and the direct involvement of checkout managers in customer service are vital to understand what kind of oppositional practices these FLSMs devised. The table below groups and illustrates the dimensions of misbehaviour and actions within those.

\section{Insert table about here}

As the table shows, FLSMs misbehaving actions are similar to those described in Ackroyd and Thompson's framework, which focuses on employees. This article shows that FLSMs not only resist corporate demands like their subordinates (see LaNuez and Jermie 1994), but also devise practices which are similar to workers. This shows that HRM research has failed to recognize that FLSMs are a distinct group with the management team who, similarly to their subordinates, are experiencing pressures and express discontent within the complex service employment relationship. HRM scholars and HR practitioners will need to re-examine the roles of FLSMs in organizations, recognize the variety of interests within management, and step away from rhetoric discourses of harmony and unproblematic devolvement of HR and managerial tasks to the front-line. 
The variety of interests is also evident when discussing FLSMs at the same level, yet across different departments. Although oppositional actions from both groups of FLSM discussed in this study (checkout and shop floor) 'fit' under the same headings, each group devised different tactics (and at different degrees) to appropriate scarce and contested resources depending on the level of customer interaction and their position on the shop floor. Shop floor managers, who enjoyed wider shop floor mobility, appropriated time and effort by stepping away from the shop floor. In contrast, checkout managers, who were constantly present on the front-end, appropriated their effort through adjusting the speed of providing support to employees, urging to take control of the intensity of their job and securing individual autonomy within the customer service.

In addition, checkout managers were found to utilize rituals of humour and gossip to 'ridicule' the customer and to undermine senior manager's authority (Taylor and Bain, 2003). In addition they avoided dealing with rude customers as a way to distance themselves from customer interaction and reacted to the conflicting pressures within the triangular service relationship. Although these mechanisms were not used as often by shop floor managers, the latter were the only ones found to 'appropriate product' through actions of pilferage. Again, their higher shop floor mobility allowed them to utilize this form of misbehaviour. These actions were not simply deviation from rules of conduct, but a behavioural innovation aiming to express resentment against management for reducing their rewards and income (Thornthwaite and McGraw, 2012). Interestingly, senior management, in both cases, have described all these behaviours as 'unsuited' for any manager, mistakenly assuming common interests and expectations of loyalty across the management team (Geare et al 2014). This research provides an important insight in managerial (mis)behaviour, and shows that FLSMs indeed misbehave and express agency within the trilateral service relationship and the expansion of their role. This evidently rejects the HRM unitarist assumption of harmony within organizations and across management levels. 
The variation, however, of oppositional actions across the front-line management agrees with previous arguments that line managers are not a homogenous group (Townsend, 2014). Therefore, actions of discontent by FLSMs are significant to be understood even at the same level of analysis. We cannot infer that all FLSMs would encounter the same pressures within the service triangle (see for example Bolton and Houlihan, 2010), hence it is erroneous to deduce a similar labour process for these managers and over-generalize their battling actions. Scholars should re-evaluate the assumptions made for the involvement of FLSMs in managerial tasks and more research should examine and discuss the contested realities on the service frontline. Similarly HR practitioners should recognize the variety of interests within management and appropriately re-organize front-line managerial work.

In conclusion, although the focus of this study was on a specific national and sectoral context, the important empirical insight of this study relates to managerial misbehaviour, as well as the identification of divert oppositional practices, even at the same level of management. This significantly contributes to our understanding of managerial ideology, managerial labour process and managerial misbehaviour. Further research in other national and interactive service contexts is necessary to better understand these concepts in the contemporary service economy. 


\section{References}

Ackroyd, S. and Thompson, P. (1999), Organizational Misbehaviour, Sage Publications, London; Thousand Oaks.

Ackroyd S and Thompson P (2016) Unruly Subjects: Misbehaviour in the Workplace In The SAGE Handbook of the Sociology of Work and Employment, edited by Stephen Edgell, Heidi Gottfried and Edward Granter (2016), London: Sage Publications.

Armstrong, P. (1989), "Management, Labour Process and Agency", Work, Employment and Society, Vol.3 No.3, 307-322.

Bélanger, J. and Edwards, P. (2013), “The nature of front-line service work: distinctive features and continuity in the employment relationship", Work, Employment and Society, Vol.27 No.3, 433-450.

Bolton, S.C. and Houlihan, M. (2010), "Bermuda Revisited?: Management Power and Powerlessness in the Worker-Manager-Customer Triangle", Work and Occupations, Vol.37 No.3, 378-403.

Child, J. and Partridge, B. (1982), Lost Managers: Supervisors in Industry and Society, CUP Archive.

Geare, A., Edgar, F., Harney, B., Cafferkey, K., and Dundon, T. (2014). 'Exploring the Ideological Undercurrents of HRM: Workplace Values and Beliefs in Ireland and New Zealand'. International Journal of Human Resource Management, Vol.25 No.16, 22752294.

Gilbert, C., De Winne, S., \& Sels, L. (2015). Strong HRM processes and line managers' effective HRM implementation: A balanced view. Human Resource Management Journal, Vol.25 No.4, 600-616 
Guest, G., Bunce, A. and Johnson, L. (2006), "How Many Interviews Are Enough?: An Experiment with Data Saturation and Variability", Field Methods, Vol.18 No.1, pp.59-82.

Hales, C. (2001), Managing Through Organization: The Management Process, Forms of Organization and the Work of Managers, Cengage Learning EMEA.

Janssens, M., and Steyaert, C. (2009), 'Point-counterpoint HRM and Performance: A Plea for Reflexivity in HRM Studies,' Journal of Management Studies, Vol.46, No.1, 143155.

Keenoy T. (1999), 'HRM as Hologram: A Polemic,' The Journal of Management Studies, Vol.36, No.1, 1-23

Korczynski, M. (2013), "The customer in the sociology of work: different ways of going beyond the management-worker dyad", Work, Employment and Society, Vol.27 No.6, NP1-NP7.

Korczynski, M. \& Evans, C. (2013) 'Customer abuse to service workers: an analysis of its social creation within the service economy' Work, Employment and Society Vol.27 No.5, 768784

LaNuez, D. and Jermier, J.M. (1994), "Sabotage by managers and technocrats: Neglected patterns of resistance at work" in Jermier, J.M., Knights, D., Nord, W.R., 1994. Resistance and power in organizations : agency, subjectivity and the labour process. Routledge, London, 219-251.

Lloyd, C. and Payne, J. (2014), “'It's all hands-on, even for management': Managerial work in the UK cafe sector", Human Relations, Vol.67 No.4, 465-488.

Lopez, S.H. (2010), "Workers, Managers, and Customers: Triangles of Power in Work Communities", Work and Occupations, Vol.37 No.3, 251-271. 
Lundberg, H. and Karlsson, J.C. (2011), "Under the clean surface: working as a hotel attendant", Work, Employment and Society, Vol.25 No.1, 141-148.

Partington D (2002) “Essential Skills for Management research” London: SAGE Publications Ltd

Richards, J. (2008). The many approaches to organizational misbehavior: A review, map and research agenda. Employee Relations, Vol. No.6, 653-678.

Royle, T. (2000) Working for McDonald's in Europe: The Unequal Struggle? London and New York: Routledge.

Saunders, M., Lewis, P. and Thornhill, A. (2009), Research Methods for Business Students., Pearson Education, Harlow.

Taylor, P., Bain, P., 2003. Subterranean Worksick Blues: Humour as Subversion in Two Call Centres. Organization Studies Vol.24, No.9, 1487-1509.

Thompson, P. (2016), "Dissent at work and the resistance debate: departures, directions, and dead ends", Studies in Political Economy, Vol.97 No.2, 106-123

Townsend, K. and Hutchinson, S. (2017), "Line managers in industrial relations: Where are we now and where to next?", Journal of Industrial Relations, Vol. 59 No.2, 139-152

Townsend, K (2014) The role of line managers in employee voice systems. In: Wilkinson, A, Donaghey, J, Dundon, $\mathrm{T}$ (eds) Handbook of Research on Employee Voice, Cheltenham: Edward Elgar, 155-169.

Thornthwaite L, and McGraw P, (2012), Still "Staying Loose in a Tightening World”? Revisiting Gerald Mars' Cheats at Work, in Barnes A and Taksa L (ed.) Rethinking Misbehavior and Resistance in Organizations (Advances in Industrial and Labor Relations, Vol.19) Emerald Group Publishing Limited, 29-55 
Willmott, H. C. (1984), Images and Ideals of Managerial Work: A Critical Examination of Conceptual and Empirical accounts. Journal of Management Studies, 21: 349-368

Willmott, H.: 1997, 'Rethinking Managerial Work: Capitalism, Control, and Subjectivity', Human Relations Vol.50 No.11, 1329-1359.

Van Buren III, H., Greenwood, M., and Sheehan, C. (2011), 'Strategic human resource management and the decline of employee focus', Human Resource Management Review, Vol.21, 209-219.

Van Denbroek, D and Dundon, T (2012), (Still) Up to No Good: Reconfiguring Worker Resistance and Misbehaviour in an Increasingly Unorganized World, Relations Industrielles/Industrial Relations, Vol.67 , No.1, 97-121

Van Waeyenberg T. and \& Decramer A. (2018) Line managers' AMO to manage employees' performance: the route to effective and satisfying performance management, The International Journal of Human Resource Management DOI: $10.1080 / 09585192.2018 .1445656$ 
Table: FLSMs and dimensions of misbehaviour

\begin{tabular}{|c|c|c|}
\hline Appropriation of time and work & Appropriation of identity & Appropriation of product \\
\hline $\begin{array}{l}\text { Effort - bargaining } \\
\text { - } \quad \text { Both Checkout and shop } \\
\text { floor managers } \\
\text { - } \quad \text { Variation in tactics } \\
\text { Time appropriation } \\
\text { - } \quad \text { Both checkout and shop } \\
\text { floor managers } \\
\text { - Variation in tactics } \\
\\
\text { Avoiding rude customers } \\
\text { - } \quad \text { Mainly checkout } \\
\text { managers } \\
\text { - Shop floor managers to a } \\
\text { lesser degree } \\
\text { - Variation in tactics }\end{array}$ & $\begin{array}{l}\text { Avoiding managerial } \\
\text { responsibility } \\
\text { - } \quad \text { Both Checkout } \\
\text { and shop floor } \\
\text { managers } \\
\text { - } \quad \text { Similar tactics } \\
\text { Gossiping, 'bitching' and } \\
\text { joking rituals } \\
\text { - } \quad \text { Mainly checkout } \\
\text { managers }\end{array}$ & $\begin{array}{l}\text { Thefts and pilfering } \\
\begin{array}{l}\text { - } \text { Only Shop floor } \\
\text { managers/mobility }\end{array}\end{array}$ \\
\hline
\end{tabular}

